\title{
6. Der negative Büschel mit Stiel und Zweigen in freier Luft;
}

von W. Holtz.

Nennt man eine kleine lautlose elektrische Lichterscheinung an Spitzen Glimmlicht, so tritt das negative Glimmlicht viel seltener als das positive und immer nur bei geringer Spannung auf. Meistens erscheint statt seiner eine kleine kegelförmige Erscheinung von rötlicher Farbe mit zirpendem Geräusch, aus unzähligen feinen, dicht aneinander gedrängten Linien gebildet, die bei Kugeln unruhig von einer Stelle zur anderen hüpft. Der negative Büschel ist also für gewöhnlich stiel- und zweiglos, da man die kleinen geraden, divergierenden Fäden keine Zweige zu nennen pflegt.

$\mathrm{DaB}$ ein negativer Büschel auch Stiel und Zweige haben könne, sah ich erst 1875, als ich ihn bei hoher Spannung aus einer gröBeren Kugel treten lieb. ${ }^{1}$ ) Dann fand ich, daB man ihn auch durch seidene Umhüllungen, durch dicke Belege von Seidenpapier nnd durch AusfluB von Leuchtgas erzeugen könne. $\left.{ }^{2}\right)$

Später wurden bei der Entladung von Induktorien und Leydener Flaschen an unterseitig belegten Glasplatten ähuliche negative Büschelformen entdeckt, von Antolik ${ }^{3}$ ) und Villari ${ }^{4}$ ) an Lichtenbergschen Figuren, von Brown ${ }^{5}$, Trouvelot ${ }^{6}$ ) und Blïmel ${ }^{7}$ ) an Photographien. Dies gehört eigentlich nicht

1) W. Holtz, Pogg. Ann. 156. p. 493. 1875.

2) W. Holtz, Wied. Ann. 11. p. 513. 1880; Carls Rep. 1881. p. 487; ebenda p. 343; Mitt. d. naturw. Ver. f. Neuvorp. u. Rügen 1881. p. 83.

3) K. Antolik, Wied. Ann. 15. p. 475. 1882.

4) E. Villari, Mem. di Bologna (4) 3. Mai u. Nov. 1882.

5) J. Brown, Phil. Mag. (5) 26. p. 502. 1888.

6) E. Trouvelot, Lum. électr. 30. p. 269.1888.

7) A. Blamel, Programmarb. der 7. stidt. Realschule zu Berlin. Ostern 1898. 
hierher, da ich hier nur die konstante Büschelerscheinung in freier Luft behandeln will. Aber es waren doch die genannten Arbeiten, welche mein Interesse an ihr wieder wach riefen und mich veranlaBten, darüber weitere Versuche anzustellen.

Bei diesen Versuchen fand ich, $\mathrm{daB}$ es noch andere als die früher von mir benutzten Darstellungsmethoden gäbe und fand auch in den Erscheinungen bisher noch unbeachtete Einzelheiten heraus, und dies bewog mich, gedachtem Büschel, den ich bisher immer nur gelegentlich beschrieben, eine besondere und umfassendere Mitteilung zu widmen. Ich schicke

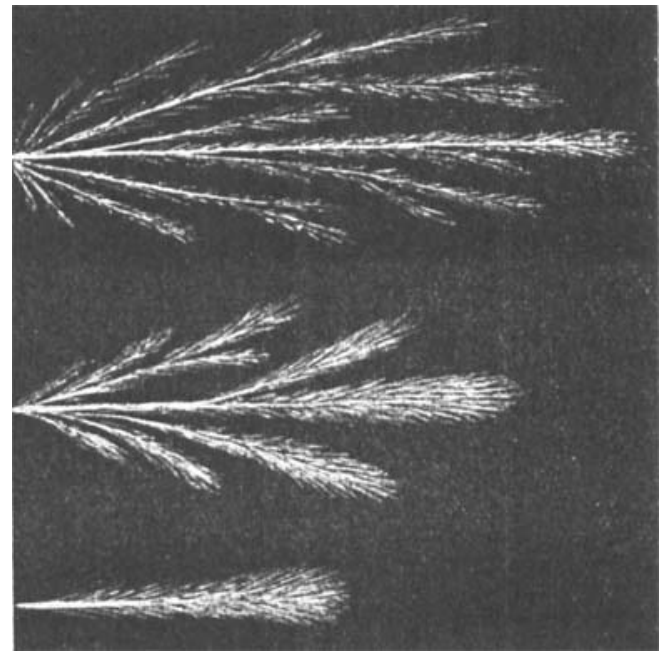

voraus, daB ich eine Influenzmaschine mittlerer GröBe benutzte, welche im Maximum Funken von $20 \mathrm{~cm}$ gab, und dab ich zur positiven Elektrode immer eine gröBere Hohlscheibe hatte, wobei es wenig Unterschied machte, ob sie isoliert oder abgeleitet war. Auch bemerke ich noch, daB ich zwar drei Grundtypen unterscheide, wie sie in vorstehender Figur in natürlicher GröBe gezeichnet sind, daß diese jedoch selbst bei derselben Darstellungsmethode mit Änderung der Spannung teilweise ineinander ubergehen.

1. Der schlanke, langgestielte Büschel. Nimmt man nach und nach gröBere Kugelu, so wächst der kleine negative Büschel 
mit abnehmender Tonhöhe allmählich zu der in der Figur unten gezeichneten Erscheinung heraus. Das Maximum der Länge erreicht man mit einer Kugel von $7-9 \mathrm{~cm}$ Durchmesser, wenn man sie der Hohlscheibe so weit annähert, daB eben noch kein Funke entsteht. Es ist ein nach vorne dicker werdender Stiel mit einer rötlichen Mittellinie, seiner ganzen Länge nach mit feinen leuchtenden Linien besetzt, welche sich dem Stiele anschmiegen und am vordersten Ende ein Bild formieren, das einem Haarpinsel gleicht. Eine ähnliche Erscheinung, aber mit grüner Mittellinie, erhält man, wenn man aus einer kleinen durchbohrten Kugelelektrode Leuchtgas flieBen läBt. Das sehr einfache Verfahren hierbei habe ich früher angegeben, muB aber hinzufügen, daB die meisten Kautschukröhren heute leiten, so daB noch eine Ebonitröhre einzuschalten ist.

2. Der kurzgestielte Büschel mit.Seitenzweigen. Dieser Büschel (siehe die Mitte der Figur) entsteht, wenn man größere Kugeln mit 6-10 facher Seide oder mehrfacher Watte umwickelt, am schönsten aber durch einen Haufen Seidenpapier, den man vor die Spitze oder besser noch vor die kleinste Kugelelektrode bringt. Schon ein einziges Blättchen an die Spitze gelegt, an der vorher Glimmlicht war, ändert dieses in einen kleinen Büschel um, da man sofort ein leises Zirpen hört. Weitere hinzugefügte Blütter vergrößern ihn, den Ton vertiefend, und bei $100-150$ Blatt tritt mit fast brummendem Geräusche die in der Figur dargestellte Erscheinung auf. Am einfachsten ist es, wenn man 1-2 Buch Seidenpapier einmal zusammenlegt und, es in der Hand haltend, vor der Spitze herabhängen läBt, aber es ist unbequem, insofern man für die Annäherung der Elektroden diese Hand dann nicht zur Verfügung hat. Ich benutzte deshalb einen $17 \mathrm{~cm}$ großen Ebonitring mit Stiel und $\mathrm{FuB}$ und brachte an diesem mittels kleiner Schräubchen oder zu Klammern gebogener Ebonitstreifen die vorher rund geschnittene Papiermasse an. Ich glaube aber, daß ein Holz- oder Pappring, isoliert unterstützt, sich ebensogut gebrauchen läBt. An der Erscheinung ist charakteristisch, daB die $Z_{\text {weige, }}$ welche übrigens dem Hauptstamm und mit diesem dem erstgenannten Büschel gleichen und ihrerseits nur wenig wieder verzweigt sind, in auffallend gerader Richtung 
gehen. Ich bemerke dies, weil die negativen Büschel der anfangs gedachten Entladungsfiguren gewöhnlich sehr krumme Zweige haben. Übrigens sieht der wirkliche Büschel wegen der beständigen Änderung seiner Teile nicht so steif aus, als das ihn darstellende Bild. Betrachtet man ihn genauer, so sieht man kleinere oder gröBere dunkle Stellen in den Zweigen, namentlich in denen, welche bis an die Hohlscheibe gehen. Zuweilen schlägt aus dieser eine merkwürdig gekrümmte Lichterscheinung, halb Funke, halb Büschel, nach den Zweigen des negativen hin, ohne in letztere tuberzugehen. Es gibt noch ein anderes Mittel zur Gewinnung gedachten Büschels, wozu es einer über die Entladungsstange gesteckten Ebonitröhre bedarf, welche vor der Spitze eine $0,7 \mathrm{~mm}$ weite und $2-3 \mathrm{~cm}$ lange Öffnung hat. Ein solches Loch läBt sich mit einem Bohrer nicht gut bohren, aber man kann dickwandige Röhren mit so engen Löchern aus der Fabrik beziehen und dann mit einem größeren Bohrer soweit aufbohren, als sie die Stange umfassen sollen. Leider läBt der Effekt solcher Röhren nach, wahrscheinlich, weil sich durch Zersetzung des Kautschuks in ihnen Kohlenstoff ablagert und sie so leitend macht. Ich versuchte sie durch entsprechend weite in feine Spitzen ausgezogene Glasröhren zu ersetzen, aber stets mit negativem Erfolg.

3. Der stiellose Büschel mit reicher Verzweigung. Man erhält ihn am schönsten mit einem elektrisch durchbohrten Glasstück von $1 \mathrm{~cm}$ Dicke, aus dem man den Büschel treten läBt. Für die Durchbohrung nimmt man eine $12 \mathrm{~cm}$ lange Ebonitröhre mit feiner Öffnung, die man $10 \mathrm{~cm}$ lang erweitert, so daB sie über die Entladungsstange paBt und schiebt in den engen $2 \mathrm{~cm}$ langen Teil eine Nadel. Die Röhre mag im Durchmesser $3 \mathrm{~cm}$ dick sein. Die senkrecht gedrehte Endfläche und die eine Seite des etwas gröBeren Glasstückes werden dann abwechselnd über einer kleinen Spiritusflamme vorsichtig so lange erwärmt, bis leichtflüssiger Wachskitt auf ihnen schmilzt, worauf man sie fest zusammenpreBt. Für die Durchbohrung wendet man zunächst eine gröBere das Glas berührende Kugelelektrode an, die man für die Darstellung des Büschels wieder mit der Hohlscheibe vertauscht. Der so erzeugte Büschel (vgl. die Figur oben) hat mehr Zweige als 
der letztgenannte, die aber dunner sind und fast alle an der Glasfläche beginnen. Man könnte sagen, daB der Stiel in diesem Falle im Glase stecke, aber dies ändert nichts an der Sache, daB die meisten Zweige denselben FuBpunkt haben. Der Effekt bleibt hier konstant, so daB man dasselbe Stück wiederholt benutzen, auch von der Ebonitröhre abschlagen und für den Gebrauch wieder ankitten kann. Eine ähnliche Erscheinung, die aber nicht so schön ist, erhält man, wenn man eine weite Ebonitröhre über die Stange bringt und rings um letztere und vor die Spitze Watte prebt.

Nach Nahrwoldts ${ }^{1}$ ) Versuchen lieB sich erwarten, daB Staub ein wichtiger Faktor bei der Erzeugung und Gestaltung elektrischer Lichterscheinungen sei. Mehr Staub in der Luft muBte sie begünstigen und also auch den negativen Büschel länger und umfangreicher machen. Ich lieB deshalb, während die Maschine tätig war, Lykopodium und anderen Staub zwischen die Flektroden fallen. Aber ich sah nicht die mindeste Veränderung und lege seitdem der Mitwirkung des Staubes überhaupt keine Bedeutung mehr bei. Gegen die Staubtheorie spricht auch die Ozonisierung der Luft, weil sie zeigt, daB die Luftmoleküle selbst von der Elektrizität ergriffen werden. Übrigens fand ich selbige besonders stark bei den großen negativen Büscheln, was wohl damit zusammenhängt, daB diese nur bei hoher Spannung entstehen.

Aber was mag der Grund sein, daB diese Büschel so schwer erzeugt werden, während die positiven von gleicher GröBe viel leichter entstehen, und daB bei beiden Sorten auch die Struktur eine so ganz andere ist? Es wäre möglich, daB der Sauerstoff der Luft von der positiven Elektrode angezogen und an ihr verdichtet hier eine Art isolierender Hülle schafft, welche das Glimmlicht hemmt und so hier eher eine höhere Spannung erzeugt, während man an der negativen eine solche Hülle erst künstlich anbringen muB, um ein Gleiches zu bewirken. Hierfür spricht, daß auch an dieser ohne künstliche Hülle ein großer Büschel kommt, wenn man Leuchtgas ausflieBen läBt. Aber vielleicht ist es richtiger, alle Unterschiede der heterogenen Lichterscheinungen als Bewegungsunterschiede

1) K. Nahrwoldt, Wied. Ann. 5. p. 460. 1878 u. 31. p. 448. 1887. 
aufzufassen, sei es der k]einsten Elektrizitätsteilchen selbst, sei es der mit ihnen behafteten Massenteilchen. Hierfür spricht, daB die fraglichen Unterschiede um so anffälliger sind, je beweglicher das betreffende Medium ist, da sie in der Luft gröBer als in isolierenden Flüssigkeiten und in diesen wieder größer als in festen Isolatoren sind. Gewib ist, dab wir die Unterschiede der beiden Elektrizitäten dort am ehesten erkennen werden, wo sie sich am deutlichsten zeigen; und das sind die Lichterscheinungen und namentlich die Büschel. Ein weiteres Studium dieser kann der Aufgabe, deren Lösung wir erstreben, also nur förderlich sein.

(Eingegangen 3. Mai 1805.) 